\title{
Vulnerabilidade Social: \\ O Psicodiagnóstico como Método de Mapeamento de Doenças Mentais
}

Social Vulnerability:

Psychological Assesment as a Mapping Method of Mental Diseases

Vulnerabilidad Social: el Psico-diagnóstico como Método de Mapeo de Dolencias Mentales

Leila Grana

Contemporâneo

Instituto de Psicanálise e Transdisciplinaridade

André G. Bastos Universidade Federal do Rio Grande do Sul /

Contemporâneo Instituto de Psicanálise e Transdisciplinaridade
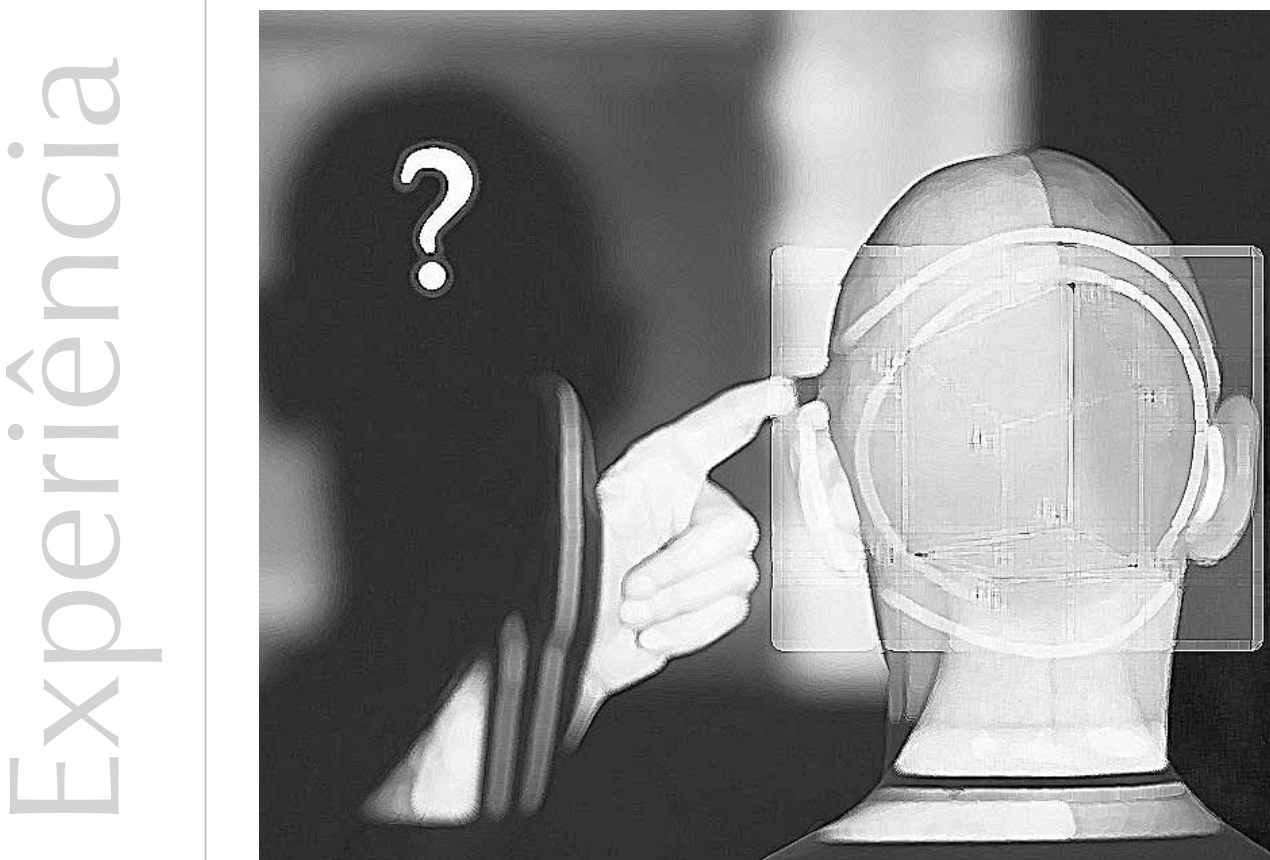
Resumo: O presente estudo demonstra a experiência de trabalho em um Centro de Referência de Assistência Social do interior do Rio Grande do Sul. Foi realizado um mapeamento de doenças mentais na população em vulnerabilidade social, através do processo de psicodiagnóstico, em caráter de estudo-piloto. Foram escolhidos três sujeitos como amostragem: uma mulher, uma adolescente e um menino. Foram analisados os fatores psicossociais, e os resultados revelaram que essa população está mais sujeita ao desenvolvimento de psicopatologias. O estudo demonstrou que a inserção do psicodiagnóstico pode contribuir como instrumento de diagnóstico da população. É necessário que haja interesse por parte das políticas públicas em ofertar os serviços de saúde à população para trabalhar com os fatores de risco socioemocionais de maneira satisfatória. Palavras-chave: Vulnerabilidade. Psicodiagnóstico. Distúrbios mentais. Políticas públicas.

\begin{abstract}
This study demonstrates the experience of working in a Reference Center of Social Welfare of the state of Rio Grande do Sul. A mapping of the mental illnesses of the population in social vulnerability was carried out, through the process of psychological diagnosis, as a pilot study. Three subjects were chosen as sample: a woman, a female teenager and a boy. The social and psychological factors were analyzed. The pilot study showed that the inclusion of psychological diagnosis can contribute as an important diagnostic tool of the population. However, it is necessary that public policy offers the proper health services to the population as a strategy to the work with risk factors.
\end{abstract}

Keywords: Vulnerability. Psychological diagnosis. Mental disorders. Public policy.

Resumen: El presente estudio demuestra la experiencia de trabajo en un Centro de Referencia de Asistencia Social del interior de Rio Grande do Sul. Fue realizado un mapeo de dolencias mentales en la población en vulnerabilidad social, a través del proceso de psico-diagnóstico, en carácter de estudio-piloto. Fueron escogidos tres sujetos como muestreo: una mujer, una adolescente y un niño. Fueron analizados los factores psicosociales, y los resultados revelaron que esa población está más sujeta al desarrollo de psicopatologías. El estudio demostró que la inserción del psico-diagnóstico pode contribuir como instrumento de diagnóstico de la población. Es necesario que haya interés por parte de las políticas públicas en ofertar los servicios de salud a la población para trabajar con los factores de riesgo socioemocionales de manera satisfactoria.

Palabras clave: Vulnerabilidad. Psico-diagnóstico. Transtornos mentales. Políticas públicas.

A partir de nossa experiência profissional, observamos que famílias economicamente carentes apresentam diversos desajustes familiares e sociais. Sabemos que a vulnerabilidade social não é fato recente em nossa sociedade, e nela estão embutidas precariedades de diversos segmentos, tais como habitação, saneamento básico, educação e saúde.

Diante do contato com as famílias que pertencem à área de abrangência do Centro de Referência de Assistência Social (CRAS), percebemos que inúmeras delas possuíam dificuldades financeiras, emocionais e psicológicas. Nesse sentido, buscamos realizar, através do psicodiagnóstico, um mapeamento emocional da população no formato de estudo-piloto, a fim de melhor identificar e compreender as dificuldades de ordem psíquica.

Para ilustrar o presente artigo, utilizaremos três estudos de caso. São eles: uma adulta do sexo feminino, de 44 anos de idade, um menino de 10 anos de idade e uma adolescente de 13 anos. Todos os sujeitos são moradores de um bairro de baixa renda em um Município do interior do Rio Grande do Sul.

As avaliações incluíram entrevistas clínicas, grafismos, H.T.P. (House - Tree - Person), Teste das Fábulas de Düss, hora de jogo diagnóstica, técnica de Rorschach, Escalas Wechsler de Inteligência (WISC III e WAIS III) e Teste Gestáltico Visomotor de Bender, do Sistema de Pontuação Gradual (B-SPG).

\section{Desenvolvimento}

Diante das precárias condições no espaço social brasileiro, o Governo Federal, através do Ministério do Desenvolvimento Social e Combate à Fome (MDS), firmou parceria com a nova Política Nacional da Assistência Social (PNAS/2004) com o intuito de investir em uma rede articulada de proteção social às famílias vulneráveis. A nova proposta da PNAS/2004 
reorganiza os projetos, programas, serviços e benefícios, indicando a implantação do Sistema Único da Assistência Social (SUAS) no território nacional.

A proteção social tem como objetivo prevenir situações de risco por meio do desenvolvimento de potencialidades e aquisições e do fortalecimento de vínculos familiares e comunitários. Nesse sentido, foram implantados os Centros de Referência de Assistência Social (CRAS) em comunidades de baixa renda com o propósito de atuar na inclusão e garantir os direitos sociais, que são o direito à renda, a segurança alimentar e a assistência social.

O CRAS é a unidade pública estatal responsável pela oferta de serviços de proteção social básica da assistência social. Nele é ofertado o Programa de Atenção Integral à Família (PAIF), que é proporcionado através de serviços socioassistenciais, socioeducativos e de convivência, além de oficinas de inclusão produtiva.

Um dos profissionais que compõe a equipe técnica do CRAS é o psicólogo, e é através de visitas domiciliares e trabalhos em grupo que a equipe busca realizar o fortalecimento dos vínculos familiares e comunitários. Em Psicologia, "vulnerabilidade refere-se a uma predisposição individual para apresentar resultados negativos no desenvolvimento, ou seja, aumenta a probabilidade de um resultado negativo ocorrer na presença de um fator de risco" (Masten \& Gamerzy, 1985).

Historicamente, a população vulnerável está inserida na sociedade em espaços estigmatizadores, conforme menciona Wanderley (2001):

A pobreza contemporânea tem sido percebida como um fenômeno multidimensional que atinge tanto os clássicos pobres (indigentes, subnutridos, analfabetos...) quanto outros segmentos da população pauperizados pela precária inserção no mercado de trabalho (migrantes discriminados, por exemplo).
Não é resultante apenas da ausência de renda; incluem-se aí os outros fatores como o precário acesso aos serviços públicos (grifos nossos) e, especialmente, a ausência de poder. Nessa direção, o novo conceito de pobreza se associa ao de exclusão, vinculando-se às desigualdades existentes e especialmente à privação de poder de ação e representação. (p. 23)

Apesar de a pobreza ser fato histórico, a discussão a respeito desse tema somente adentrou a comunidade científica e as organizações internacionais a partir da década de 90. Especialmente nas Organizações das Nações Unidas (ONU), surgiu o Programa das Nações Unidas para o Desenvolvimento (PNUD), que visa ao combate à pobreza no trabalho junto aos governos, iniciativa privada e sociedade civil, por reconhecer que há um número expressivo de sujeitos que vivem em precárias condições. Nesse sentido, um dos objetivos dos países que fazem parte desse Programa, inclusive o Brasil, é reduzir a pobreza extrema até o ano 2015.

Ainda de acordo com o PNDU, no Brasil, atualmente (dados de 2008), 7,5 milhões de brasileiros ainda têm renda domiciliar inferior a um dólar por dia. Frente a essa realidade, existem algumas iniciativas por parte dos governos na tentativa de mudar tal cenário social (http://www.pnud.org.br/pnud/).

Nas famílias, além de visualizarmos a problemática social, também identificamos o sofrimento psíquico de seus membros. Nossa experiência mostra que, frente ao profissional de saúde mental, o sujeito em sofrimento tende a descarregar suas aflições e angústias. Apesar de a proposta do PAIF ser voltada para os trabalhos de grupo visando ao fortalecimento dos vínculos familiares e/ou comunitários, existem situações em que urge realizarmos a psicoterapia individual por identificarmos intenso sofrimento psíquico.

Conforme levantamento realizado no CRAS, em três anos, 447 famílias foram cadastradas. De acordo com dados obtidos no Programa 
Saúde da Família (PSF), que atua na mesma área de abrangência do CRAS, existem 629 famílias, totalizando um número de 2.026 sujeitos. Mensuramos 152 sujeitos que buscaram ou foram encaminhados ao atendimento psicológico. No entanto, a continuidade do acompanhamento se dá em muito poucos casos, em virtude da desistência do paciente (104 sujeitos desistiram do atendimento).

Dentre as problemáticas existentes, depressão, alcoolismo/drogadição e dificuldades de aprendizagem são as mais frequentes. Diante da grande demanda, realizamos o encaminhamento a outro profissional da rede pública. Normalmente, as pessoas precisam deixar suas angústias e aflições em uma lista de espera sem tempo previsto para serem atendidas, uma vez que não há profissionais em número e capacitação suficientes para realizar o trabalho no Município. A questão da doença dos nervos é abordada por Costa (1989) como um adoecer mental espalhado pela população de baixa renda, e isso aparece muito nos relatos de nossos usuários.

Apesar de o processo psicodiagnóstico não fazer parte das atividades propostas pelo Programa, percebemos uma demanda e uma oportunidade de mapear a população utilizando esse processo para avaliar as doenças mentais e/ou demais dificuldades que possam estar vivenciando no âmbito psicológico. Essa escolha foi feita por se tratar de método estrutural que nos permite obter tanto dados qualitativos como quantitativos dos sujeitos avaliados.

Considerando o sofrimento emocional inerente ao sofrimento socioeconômico, o presente estudo-piloto buscou mapear tanto as doenças mentais como as possíveis dificuldades dessa população vulnerável. Dessa forma, acreditamos que a realização do psicodiagnóstico seja um procedimento válido na busca de investigar as principais demandas dos munícipes concernentes à saúde mental. Segundo Cunha (2000), um dos objetivos do psicodiagnóstico é a prevenção, isto é, a identificação dos problemas de maneira precoce, a avaliação de riscos e a realização de uma estimativa de força dos sujeitos para o enfrentamento de situações difíceis, novas e estressantes. Essa autora ainda acrescenta:

O psicodiagnóstico é um processo científico, limitado no tempo, que utiliza técnicas e testes psicológicos (input), em nível individual ou não, seja para entender problemas à luz de pressupostos teóricos, identificar e avaliar aspectos específicos, seja para classificar o caso e prever seu curso possível, comunicando os resultados (output) na base dos quais são propostas soluções, se for o caso. (p. 26)

De acordo com Arzeno (1995), o processo psicodiagnóstico inclui as entrevistas iniciais com familiares, a hora de jogo e o uso de testes. No que tange aos propósitos, são de estabelecer o diagnóstico e, em consequência, avaliar o prognóstico e as devidas estratégias para ajudar o sujeito frente as suas problemáticas.

Pensando no psicodiagnóstico como um trabalho rico em informações obtidas a partir das estratégias de instrumentalização regulamentadas pelo Conselho Federal de Psicologia (CFP), podemos inferir que a avaliação tem muito a contribuir com a questão pública. Ainda conforme Arzeno (1995), através do psicodiagnóstico, podese chegar mais próximo dos motivos do sofrimento dos sujeitos.

Descreveremos os casos para exemplificar as dificuldades psicológicas vividas por essa população. Cabe ressaltar que todos os procedimentos éticos foram seguidos, incluindo a assinatura do Termo de Consentimento Livre e Esclarecido por parte dos participantes e/ou responsáveis.

\section{Caso A:}

Paciente do sexo feminino, 44 anos, casada, 05 filhos, ensino fundamental incompleto, do lar. Após envolver-se em mais uma briga, em que, de um lado, estava o esposo, e de outro, o 
filho primogênito juntamente à companheira, sendo que ambos os lados faziam uso de facas, a paciente deu baixa hospitalar em nosso Município. No hospital, fez um breve tratamento clínico e, em seguida, foi encaminhada ao CRAS. A paciente chegou até nós extremamente debilitada, muito magra, conforme prontuário médico do PSF. Constava, ainda, que a paciente apresentava dores no corpo e cefaléia, ansiedade, tremores, fala lenta e baixa bem como sintomas depressivos. Dentre alguns sintomas depressivos, podemos citar visões desoladas e pessimistas de futuro, ideias e atos autolesivos, sono perturbado, apetite diminuído e humor deprimido.

No decorrer do acompanhamento médico, foram realizados encaminhamentos à psiquiatria; no entanto, a paciente suspendeu o uso dos psicofármacos devido a dificuldades financeiras. Tais dificuldades ainda fazem parte do histórico clínico e social dessa paciente.

O histórico da paciente também nos mostra que ela fez uso de bebidas alcoólicas durante um período de 08 anos, entre 32 e 40 anos de idade. A paciente remeteu-se à data de nascimento de sua penúltima filha, hoje com 12 anos de idade, e também à morte de seu pai para lembrar a época em que abusava do álcool. Sua aproximação com a bebida se deu a partir de dificuldades financeiras enfrentadas pela família e também da perda da figura paterna, que era referência para a paciente.

Durante acompanhamento realizado com a paciente, esta demonstrou ter raiva de bebidas alcoólicas, contudo, apenas após muita investigação ela revelou que também fez tal uso. Disse que dormia apenas quando estava alcoolizada, e que essa foi uma época muito difícil de sua vida.

O esposo, por sua vez, fez uso do álcool por um período aproximado de 25 anos, entre 17 e 42 anos de idade. Em virtude de encontrarse com problemas de saúde, o esposo cessou a ingestão de bebidas alcoólicas há cerca de um ano.
Ocorreram muitos episódios de violência física entre pai e filhos, principalmente com o primogênito, quando o primeiro se encontrava alcoolizado e o filho era ainda muito pequeno.

A violência ainda hoje marca presença nesse contexto familiar. A agressividade aparece acentuadamente no terceiro filho e na filha mais jovem, de 09 anos de idade, através de desobediência às figuras de autoridade. Há indícios de que o terceiro filho, de 15 anos, esteja fazendo uso de drogas. O adolescente também não demonstra nenhum interesse em continuar estudando, e os pais pouco o incentivam a manter a frequência escolar.

Os membros normalmente se vestem com roupas velhas, às vezes, sem serem passadas. Quando lavadas, ficam expostas à poeira e à fumaça da chaminé da casa. Os dois netos da paciente, que residem bem próximos a sua casa, normalmente necessitam de higiene corporal.

A família apresenta situação socioeconômica bastante comprometida, e isso se reflete na precária habitação. A residência de madeira é pequena e possui frestas nas paredes, o que se agrava especialmente no inverno, quando a temperatura, às vezes, é negativa.

Esse grupo familiar é beneficiário do Programa Bolsa Família (PBF) e do Programa de Aquisição de Alimentos (P. A. A.), desenvolvido mensalmente no Município. Quando há entrega da cesta de alimentos, os membros ficam envolvidos na atividade, deixando de ir à escola e/ou ao atendimento psicológico.

O resultado da avaliação mostrou que a paciente apresenta grandes dificuldades. Podemos mencionar a orientação autopsíquica prejudicada bem como o prejuízo na memória de curto e de longo prazos, com lentidão de pensamentos, ideação suicida e comportamentos automutilantes (fazer buracos na perna e tentar cortar pulsos utilizando-se de uma faca). 
A paciente, há dois anos e meio, vem realizando tratamento com médico psiquiatra, em um Município distante cerca de $200 \mathrm{~km}$. As consultas são marcadas em períodos de quatro meses, e, normalmente, a família estende esse período em virtude das dificuldades financeiras.

Durante o tratamento, várias trocas de medicamentos foram efetuadas na busca de melhorias para a saúde. Essa paciente apresenta um caso muito difícil de ser diagnosticado, pois, da maneira como os sintomas se sobrepõem, há, simultaneamente, indícios de que ela possua esquizofrenia e/ou síndrome orgânica cerebral, conforme resultado de sua avaliação. O tratamento realizado com médico psiquiatra não apresentou melhoras significativas, uma vez que também não foi possível realizar exames complementares de neuroimagem. O Município não possui convênio com as clínicas/hospitais que realizam exames dessa espécie.

Diante de tal situação, seu quadro clínico não pôde ser diagnosticado de maneira rápida na tentativa de evitar mais riscos para si mesma e para sua família. Seria útil e necessário, então, fazer uso de vias secundárias, que demandam um tempo extenso para o fechamento do diagnóstico. Essas vias se dão através de reavaliações psicológicas programadas para períodos que podem variar de 06 a 12 meses, a fim de podermos nos aproximar longitudinalmente do mais real possível em termos diagnósticos.

Por conhecermos tal realidade, ofertamos a avaliação a essa paciente, para então melhor demonstrar à família e a ela suas dificuldades, $\mathrm{O}$ seu grau de seu sofrimento e, principalmente, para propor os devidos encaminhamentos. Voltaremos a esse caso na discussão teóricoclínica.

\section{Caso B:}

Menino de 10 anos, estudante da 5ํㅗ série de uma escola pública estadual, que reside com pai, madrasta e duas irmãs.

Sua avaliação psicológica foi realizada devido à presença de comportamentos que envolviam pequenos furtos, piromania, agressividade, mentiras e desinteresse escolar.

Anteriormente a essa avaliação, não conhecíamos e não houve nenhum contato com o menino. Seu pai possui histórico familiar de envolvimento com brigas, furtos e possível tráfico de drogas. O contato entre os filhos e a mãe pouco ocorre, em virtude de ela residir em outra cidade e pouco visitar os dois filhos, que ficaram com o pai quando houve a separação do casal. Na época do novo casamento do pai, a menina tinha 6 anos, e o menino, 4 anos de idade. Assim, a madrasta tornou-se responsável pela educação e pelos cuidados com as crianças.

No que se refere à residência da família, esta é grande, de alvenaria, com quartos separados para casal e crianças. Não adentramos a casa toda, contudo, visualizamos que a mobília da sala é composta por móveis bonitos, novos e é bem limpa. Praticamente todas as vezes que fazíamos visita à família, a casa estava sendo faxinada, organizada, com muitas roupas lavadas. Todos os membros da família se vestem adequadamente, têm roupas bastante limpas e bonitas.

A família possui um veículo que, segundo a madrasta do menino, seu esposo utiliza para o trabalho. Esse trabalho é tráfico de narcóticos, camuflado com vendas de CDs e DVDs piratas. O pai do menino, por vezes, fica cerca de 15 dias fora de casa devido ao trabalho.

A avaliação foi iniciada com entrevistas com a responsável e, posteriormente, com o menino, a partir de uma estratégia de instrumentos, que incluíram: grafismos, H. T. P., hora de jogo diagnóstica, Teste Gestáltico Visomotor de Bender, Teste das Fábulas e WISC III. 
Uma das dificuldades encontradas na realização dessa avaliação foi em relação ao acesso ao pai, pois, mesmo quando solicitado por duas vezes, não aceitou nosso convite. De acordo com a madrasta, o pai é figura ausente mesmo quando presente no lar.

O pai compareceu somente no momento da devolução da avaliação, quando sua companheira não pôde se fazer presente. Os resultados da avaliação mostraram que o menino possui um lar desprovido de afeto, segurança, apoio e diálogo. Como consequência, passou a apresentar sentimentos de inadequação, descontentamento, diminuição grave em sua autoestima e também sintomas depressivos, com tendência a se afastar ainda mais de seus familiares e do meio social.

Parece-nos que, em virtude de estar inserido em um ambiente constituído de estigmas, exclusão e preconceito, bem como carência de afeto e incentivos, o menino passou a apresentar comportamentos inadequados.

A avaliação apresentou um prognóstico reservado para o caso estudado. Mesmo diante de tal prognóstico e de esclarecimentos sobre a importância de se buscar os devidos encaminhamentos, a família não efetuou nenhum movimento nessa direção.

\section{Caso C:}

Adolescente de 13 anos de idade, sexo feminino, estudante da $5^{\underline{a}}$ série de uma escola pública. Reside com a mãe, a irmã de 11 anos, o irmão de 15 anos e o padrasto.

A adolescente avaliada possui ainda dois irmãos por parte de pai. Este constituiu nova família, cuja companheira possui três filhos que não são dele.

Os pais da adolescente tiveram o relacionamento conjugal marcado por inúmeras brigas e separações. Na época do término do casamento dos genitores, a adolescente tinha aproximadamente 10 anos de idade. Cada cônjuge aponta, a partir de seus pontos de vista, diferentes fatores como desencadeadores do fim da relação. De acordo com a mãe, o abuso de bebidas alcoólicas pelo ex-companheiro foi prejudicial. O pai, por sua vez, verbaliza que sua ex-companheira não dava a devida atenção e cuidados aos filhos, além de frequentemente sair com amigas e traí-lo algumas vezes.

Quanto à renda familiar, esta é obtida a partir do trabalho da mãe e do padrasto da adolescente. A mãe prepara lanches e, no turno inverso ao da escola, a adolescente e os irmãos vendem os produtos. O padrasto trabalha em uma cidade vizinha.

A adolescente frequentava as oficinas de reforço escolar e sociopedagógicas no CRAS há dois anos, quando a mãe relatou que a filha estaria apresentando dificuldades de concentração, com baixo rendimento escolar. A adolescente apresenta histórico de repetições na $1 \underline{\underline{a}}$ e na $4 \stackrel{a}{a}$ séries.

A partir do contato já existente entre a equipe do CRAS e a adolescente, foi possível perceber que ela se apresentava de maneira bastante infantil e envergonhada se comparada com as demais adolescentes de igual idade e, principalmente, em relação à irmã mais jovem.

Assim, somando as dificuldades apresentadas pela mãe e as observações realizadas, foi dado início ao processo de avaliação com a adolescente com o objetivo de identificar suas dificuldades e potencialidades. Primeiramente, realizamos as entrevistas individuais com os genitores. Com a adolescente, foram utilizados os seguintes instrumentos: entrevistas clínicas, grafismos diversos, H. T. P., WISC- III e Teste das Fábulas.

A mãe, que, inicialmente, buscou ajuda e mostrou interesse por melhorias no rendimento e no comportamento da filha, demonstrou também ter sido a principal responsável pela desistência da mesma nas oficinas do CRAS 
bem como no processo da avaliação. A mãe deixava os afazeres domésticos para a adolescente, principalmente nos dias em que esta tinha compromisso no CRAS.

Os resultados da avaliação mostraram que a paciente se apresentava com QI total 83, isto é, em nível médio inferior, segundo WISC III, necessitando de avaliação complementar a partir de exames de neuroimagem devido a dificuldades no índice de organização perceptual e de resistência à distração, bem como de apoio psicopedagógico e de acompanhamento psicológico.

Particularmente, no que tange à avaliação dos exames de neuroimagem, estes não puderam ser realizados pelos mesmos motivos já mencionados no caso A. Convém ressaltar que esse fato prejudicou o andamento do trabalho. Não há expectativas de serem devidamente resolvidas essas questões, mas a infeliz possibilidade de seus sintomas serem intensificados com o decorrer do tempo pela ausência do tratamento adequado.

\section{Discussão Teórico-clínica}

É na família que as funções de cuidado e transmissão dos valores e das normas culturais devem ser cumpridas, produzindo assim as condições necessárias para a sua participação nos demais grupos (Bock, 1999). Esses grupos, dos quais também fazemos parte, são o bairro onde residimos, a escola, os programas e a igreja que frequentamos, dentre outros. Todos eles, conforme seus contextos, tendem a nos moldar.

De acordo com Eizirik, Kapczinski e Bassols (2001), as mudanças ocorridas na vida dos adultos são, hoje, um reflexo do meio social, cultural e econômico em que vivem os sujeitos, somado a sua história transgeracional. No que tange à identidade social, esta é constituída pelo conjunto de características individuais reconhecida pelo meio onde o sujeito está inserido. Isso significa dizer que, em um ambiente pobre do ponto de vista econômico, tende-se a criar/moldar sujeitos pobres de cultura, com rede afetiva precária e com pouco diálogo, com ausência de autonomia e baixa autoestima.

Considerando que o sofrimento psíquico é um fenômeno que perpassa todas as classes sociais, acreditamos, entretanto, que, em sujeitos vulneráveis, o sofrimento psíquico tem maior amplitude, em virtude de se ter menor possibilidade para melhorar suas relações familiares e sua qualidade de vida, uma vez que estão também desprovidos de apoio e de serviços públicos satisfatórios.

Nossas avaliações demonstraram ampla vulnerabilidade ao contexto nos três casos, cada um com a sua particularidade, mas com um fator de risco em comum: o próprio meio ambiente onde estão inseridos. Além desse importante fator de risco, existem tantos outros muito presentes nessa população, que são: a violência doméstica e social, o histórico familiar de alcoolismo/drogadição, negligências diversas por parte dos pais e/ ou responsáveis, sintomas depressivos, etc. Observamos, ainda, a evasão escolar, a ausência de rede afetiva entre familiares e o espaço que privilegie a proteção e a influência educativa, bem como a ausência de disponibilidade para aprender a lidar melhor com os filhos.

Existem inúmeros estudos que demonstram que a exposição de crianças e jovens às práticas parentais inadequadas (conflitos, violência, coerção, etc.) e baixo envolvimento familiar e socio-cultural constituem fatores de risco para o desenvolvimento e aumentam a vulnerabilidade de eventos ameaçadores (delinquência, drogas, etc.) externos ao contexto familiar (Ferreira \& Marturano, 2002; Gomide, 2003; Mc Dowell \& Parke, 2002; Marturano, 2004). 
Particularmente no que se refere à violência, esta existe de maneira exacerbada, podendo estar explícita, através dos relatos dos membros ou de sinais físicos presentes nos corpos dos sujeitos, ou camuflada, quando os sujeitos tentam negar a existência da violência física e/ou psicológica em seus lares. De qualquer maneira, o sujeito violentado tende a apresentar sintomas depressivos, pois sofre chantagens, acusações e ameaças por parte de seus responsáveis.

Na população avaliada, constatamos que em todas há a presença de abuso de drogas ou de envolvimento com tráfico por algum membro familiar. Para alguns, esse é um mecanismo de fuga da realidade, ao mesmo tempo que, para outros, é fonte de renda. Também podemos considerar que o abuso de substâncias pode ser encarado como uma tentativa de automedicação, em que o sujeito busca remediar principalmente seus sintomas mais depressivos.

Mesmo sem as devidas condições, as novas famílias vão se formando. Normalmente, não há planejamento familiar, e o número de filhos é maior do que as reais possibilidades econômicas e afetivas da família. Observamos que, nos três casos, os filhos vieram sem planejamento.

Também verificamos que, em todos os casos, os pacientes tiveram perda de um dos pais, seja em decorrência de morte, seja de separação conjugal. A separação, depois de ocorrida, deposita o compromisso para um dos responsáveis que, sem as estruturas física e/ou emocional adequadas, não consegue ofertar aos filhos o devido suporte de que tanto necessitam. Os genitores têm dificuldades em lidar com os filhos.

Nas entrevistas realizadas com os sujeitos avaliados ou com seus familiares, enumeramos várias vezes a fala: "eles (os filhos) têm de tudo", referindo-se ao aspecto econômico, quando dizem que têm o que comer, o que vestir e onde dormir. Sabemos que isso não é suficiente. De fato, os pais não percebem que os filhos estão desprovidos de afeto, de apoio e de segurança, necessários para um adequado desenvolvimento biopsicossocial.

Muito frequentemente, precisamos reafirmar a importância de um vínculo afetivo satisfatório entre os membros da família, pois nossa experiência nos mostra que, frente a carências em demasia, a falta de perspectivas, de incentivos parentais, de características de personalidade que justifiquem uma mudança, podemos dizer que o futuro reserva a eles a marginalização, o uso de álcool e/ou drogas e a prostituição, que contribuiem para que os fatores de risco venham a se manter bem presentes em seu contexto social.

É importante também assinalarmos que, dentre as problemáticas mais eminentes no público infanto-juvenil, se encontram as dificuldades de aprendizagem. Acreditamos que exista tal demanda em virtude de os pais não possuírem escolaridade suficiente para auxiliar os filhos, e apresentarem até mesmo a alegação que a responsabilidade para com o filho é apenas da instituição de ensino. Especialmente no caso B, o menino demonstra insatisfação, descontentamento através de comportamentos como piromania e agressividade na escola e em casa, como forma de dizer que está necessitando de mais atenção. O menino encontra-se vulnerável e exposto a fatores de risco.

Para mantermos a presença do público no desenvolvimento das atividades grupais, enfrentamos grande obstáculo. Por um lado, temos a impressão de que os sujeitos se sentem amedrontados por estarem conversando sobre suas experiências quando, na verdade, a população vizinha já conhece seus problemas. Por outro lado, quando conversamos sobre suas famílias, as mulheres falam simultaneamente, mostrando que precisam ser ouvidas e 
ajudadas. Avaliamos que, de maneira geral, os sujeitos de baixa renda se mostram reservados e com dificuldades de se vincular à equipe multidisciplinar, mas, quando se sentem seguros, depositam suas expectativas nos profissionais. Para assegurarmos a presença dos sujeitos nas atividades desenvolvidas objetivando auxiliá-los, foi preciso desenvolver a estratégia de atrair a população com brindes. Isso nos dá a impressão de que a atenção e o apoio devem ser fornecidos apenas mediante um pagamento, principalmente quando nos referimos às questões familiares, educacionais e afetivas. Temos que pagá-los para que aceitem se tratar.

Os sujeitos avaliados apresentam sentimentos de inadequação, baixa autoestima, são muito agressivos e inseguros e possuem pouca iniciativa. Essas características nos remetem a um ambiente empobrecido de afeto, onde as relações afetivas estão fragilizadas, com pouco vínculo e diálogo.

Os resultados também nos mostram que as mulheres são as responsáveis pelos cuidados da casa e dos filhos, enquanto o homem possui maior liberdade e é o responsável pelo sustento familiar. É uma estruturação familiar mais primitiva.

Abreu, Salzano, Vasques, Filho e Cordás (2006) revelam um dado assustador, a partir de dados estatísticos da Organização Mundial da Saúde (OMS). A depressão tem projeção para ser a quarta causa de ônus social em 2020. Nosso trabalho com a população tem nos mostrado que cresce de maneira significativa o número de pessoas com doenças mentais, como, por exemplo, a depressão. De acordo com Abreu et al. (2006), eventos estressantes, tais como perdas de entes queridos, de emprego e/ou doença e ausência de suporte social satisfatório, estão intrinsecamente relacionados ao risco de se apresentar quadro depressivo. A depressão envolve um acentuado esforço pessoal, físico e social e compreende a incapacidade individual e o desgaste emocional e financeiro suportado pelos familiares.

Evidenciamos que não pretendemos discorrer sobre a depressão, mas mencioná-la de maneira suficiente e coerente, haja vista que tal patologia é desencadeada pela soma dos fatores genético, psicológico e socioambiental e está presente nos resultados das três avaliações realizadas e aqui descritas, como morbidade principal ou como comorbidade.

Arriscamos dizer, então, que sintomas depressivos podem surgir a partir do momento em que o sujeito, independentemente de sua idade, não encontra afeto e apoio suficientes em seu grupo familiar e em sua rede de apoio social. Segundo Bock, Furtado e Teixeira (1999), diante de situações difíceis e de sofrimento intenso é que mais precisamos de pessoas que sejam continentes com nosso sofrimento, e que não devemos excluir o sujeito nem discriminálo de maneira a evitar que a problemática se torne ainda maior. Quando sozinhos, temos a tendência de nos menosprezar, ter baixa autoestima e, infelizmente, procurar nas ruas o que não encontramos em nosso lar. Diante dos resultados das avaliações, inferimos que as pessoas se apresentam com prognósticos de reservado a ruim por apresentarem aqueles sintomas e, muitas vezes, por não receberem o devido tratamento.

Considerando que Cunha (2000) define o psicodiagnóstico como um processo que busca identificar problemas de maneira precoce, avaliar riscos e realizar uma estimativa da força dos sujeitos para o enfrentamento de situações difíceis, novas e estressantes, faz sentido dizermos, então, que podemos identificar quais sujeitos são resilientes ou vulneráveis através do psicodiagnóstico. A partir de suas experiências em trabalhos com comunidades 
de baixa renda, Hutz, Koller e Bandeira (1996) afirmam:

Se desejarmos conduzir programas sociais capazes de melhorar o prognóstico e a qualidade de vida das nossas populações pobres e marginalizadas, teremos que produzir localmente o conhecimento necessário para entender com clareza qual o nível de stress produzido pelos fatores da vida cotidiana e que variáveis ou processos aumentam a vulnerabilidade ou protegem os indivíduos do risco produzido por esses eventos. (p. 84)

Sendo assim, podemos utilizar o psicodiagnóstico como método de evitar a disseminação das problemáticas e/ou doenças mentais quando realizado adequadamente. Esse processo se mostrou útil e de caráter preventivo-interventivo.

\section{Considerações Finais}

Este estudo revelou resultados tristes e persistentes, porém reais, de uma parte do cenário social brasileiro. Acreditamos que esses resultados se repitam em outras comunidades de baixa renda de todo Brasil, e talvez, do mundo.

Trabalhar com famílias de baixa renda é, simultaneamente, satisfatório e difícil, pois, de um lado, percebemos que podemos contribuir com elas quando ofertamos nossa compaixão e respeito, ou seja, quando as escutamos; por outro lado, o trabalho se torna difícil, pois, diante da complexidade das questões que cercam a miséria, parece que pouco contribuímos. No trabalho com essa população, precisamos compreender que a ajudamos a obter um nível de funcionamento mais sadio dentro de seu contexto, fazendo o que está ao nosso alcance.

Nós, profissionais de saúde, juntamente aos governos, iniciativa privada e sociedade civil, se realmente reconhecermos tamanha carência presente nos lares brasileiros, poderemos dedicar mais atenção e manifestar menos preconceitos em relação aos mesmos.

Evidenciamos que o psicodiagnóstico é um instrumento que visa a ajudar no diagnóstico dos problemas e a facilitar o planejamento objetivo das soluções, na busca da superação dos graves déficits de saúde mental que estão presentes nessas comunidades. Nesse sentido, assinalamos a importância de maior número de psicólogos buscarem a capacitação nessa área, pois ainda há muito o que fazer, principalmente com as populações vulneráveis.

Parece-nos utopia pensar que, a partir de métodos clínicos tradicionais da Psicologia, se possa curar as mazelas da sociedade e impedir o que podemos chamar de epidemia socio-emocional. Entretanto, a Psicologia, identificando e mensurando as doenças mentais distribuídas pela população, pode, através do processo psicodiagnóstico, por exemplo, contribuir com a saúde mental e/ou com a promoção da saúde dos sujeitos que se encontram em vulnerabilidade social.

Entendemos que a sociedade urge por políticas públicas capazes de bem atender as demandas da população mais carente. Caberá, assim, às autoridades e aos cidadãos buscar a implementação de políticas de saúde mental que valorizem a dignidade humana de TODOS os sujeitos. As políticas não devem ser assistencialistas, e sim, devem colocá-los como sujeitos ativos no processo de mudanças.

Sem superações, o Brasil, futuramente, continuará apresentando o retrato de uma sociedade repleta de pobreza, de exclusão social e, em consequência, de sofrimento psíquico como o mencionado neste artigo. 


\section{Referências}

\section{Leila Grana}

Especialista em Psicodiagnóstico e Avaliação Psicológica pelo Instituto de Psicanálise e Transdisciplinaridade (Contemporâneo - Instituto de Psicanálise e Transdisciplinaridade).

E-mail: leila.grana.psico@hotmail.com

\section{André G. Bastos}

Mestre em Psicologia Clínica pela Pontifícia Universidade Católica do Rio Grande do Sul , Rio Grande do Sul - RS - Brasil. (Universidade Federal do Rio Grande do Sul e Contemporâneo - Instituto de Psicanálise e

Transdisciplinaridade).

E-mail: andregbastos@terra.com.br

*Endereço para envio de correspondência:

Rua José Marcelino de Góes, 05, Centro - Rio Real -Bahia- BA - Brasil CEP 48330.000.

Recebido 21/1/2009, 1a Reformulação 26/11/2009, Aprovado 22/02/2010.

Abreu, C. N., Salzano, F. T., Vasques, F., Filho, R. C., \& Cordás, T. A. (2006). Síndromes psiquiátricas: diagnóstico e entrevista para profissionais de saúde mental. Porto Alegre: Artmed.

Arzeno, M. E. G. (1995). Psicodiagnóstico clínico: novas contribuições (B. Affonso Neves, trad.). Porto Alegre: Artmed.

Bock, A. M. B., Furtado, O., \& Teixeira, M. L. T. (1999). Psicologias: uma introdução ao estudo de psicologia (13a ed., rev. e ampl.). São Paulo: Saraiva.

Costa, J. F. (1989). Psicanálise e contexto cultural. Imaginário psicanalítico, grupos e psicoterapia. Rio de Janeiro: Campos.

Cunha, J. A. (2000). Psicodiagnóstico-V (5a ed. rev. e ampl.). Porto Alegre: Artmed.

Eizirik, C. L., Kapczinski, F., \& Bassols, A. M. S. (2001). O ciclo da vida humana: uma perspectiva psicodinâmica. Porto Alegre: Artmed.

Ferreira, M. C. T., \& Marturano, E. M. (2002). Ambiente familiar e os problemas do comportamento apresentado por crianças com baixo desempenho escolar. Psicologia: Reflexão e Crítica, 15(1), 35-44.

Gomide, P. I. C. (2003). Estilos parentais e comportamento antisocial. In A. Del Prette \& Z. A. P. Del Prette (Orgs.), Habilidades sociais, desenvolvimento e aprendizagem (pp. 21-60). Campinas, SP, Alínea.
Hutz, C., Koller, S., \& Bandeira, D. (1996). Resiliência e vulnerabilidade em crianças em situação de risco. In S Koller (Ed.), Aplicações da psicologia na melhoria da qualidade de vida. Porto Alegre: Associação Nacional de Pesquisa e Pós-Graduação em Psicologia. (Coletâneas da ANEPP, Vol.1, n.12).

Marturano, E. M. (2004). Fatores de risco e proteção no desenvolvimento sócio-emocional de crianças com dificuldades de aprendizagem. In E. G. Mendes, M. A. Almeida \& L. C. A.

Williams (Orgs.), Avanços recentes em educação especial (pp. 159-165). São Carlos, SP: EDUFSCar.

Masten, A., \& Garmezy, N. (1985). Risk, vulnerability and protective factors in developmental psychopathology. In B. B. Lahey \& A. E. Kazdin (Eds.), Advances in clinical child psychology (pp. 1-52). New York: Plenum.

Mc Dowell, D. J., \& Parke, R. D. (2002). Parent and child cognitive representations of social situations and children's social competence. Social Development, 11(4), 469-486.

Wanderley, M. B. (2001). Refletindo sobre a noção de exclusão. In Bader Sawaia, As artimanhas da exclusão: análise psicossocial e ética da desigualdade social (2a ed., pp. 16-26). Petrópolis, RJ: Vozes. 